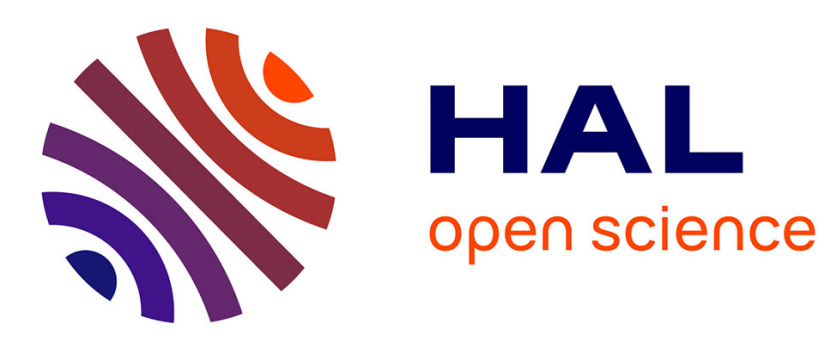

\title{
Cough and gastroesophageal reflux: from the gastroenterologist end
}

Ans Pauwels, Kathleen Blondeau, Lieven Dupont, Daniel Sifrim

\section{To cite this version:}

Ans Pauwels, Kathleen Blondeau, Lieven Dupont, Daniel Sifrim. Cough and gastroesophageal reflux: from the gastroenterologist end. Pulmonary Pharmacology \& Therapeutics, 2009, 22 (2), pp.135. 10.1016/j.pupt.2008.11.007 . hal-00516733

\section{HAL Id: hal-00516733 https://hal.science/hal-00516733}

Submitted on 11 Sep 2010

HAL is a multi-disciplinary open access archive for the deposit and dissemination of scientific research documents, whether they are published or not. The documents may come from teaching and research institutions in France or abroad, or from public or private research centers.
L'archive ouverte pluridisciplinaire HAL, est destinée au dépôt et à la diffusion de documents scientifiques de niveau recherche, publiés ou non, émanant des établissements d'enseignement et de recherche français ou étrangers, des laboratoires publics ou privés. 


\section{Accepted Manuscript}

Title: Cough and gastroesophageal reflux: from the gastroenterologist end

Authors: Ans Pauwels, Kathleen Blondeau, Lieven Dupont, Daniel Sifrim

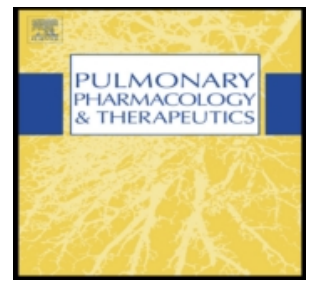

PII: $\quad$ S1094-5539(08)00126-0

DOI: $\quad$ 10.1016/j.pupt.2008.11.007

Reference: $\quad$ YPUPT 883

To appear in: Pulmonary Pharmacology \& Therapeutics

Received Date: 13 October 2008

Revised Date: 3 November 2008

Accepted Date: 15 November 2008

Please cite this article as: Pauwels A, Blondeau K, Dupont L, Sifrim D. Cough and gastroesophageal reflux: from the gastroenterologist end, Pulmonary Pharmacology \& Therapeutics (2008), doi: 10.1016/j.pupt.2008.11.007

This is a PDF file of an unedited manuscript that has been accepted for publication. As a service to our customers we are providing this early version of the manuscript. The manuscript will undergo copyediting, typesetting, and review of the resulting proof before it is published in its final form. Please note that during the production process errors may be discovered which could affect the content, and all legal disclaimers that apply to the journal pertain. 


\section{COUGH AND GASTROESOPHAGEAL REFLUX: \\ FROM THE GASTROENTEROLOGIST END}

Ans Pauwels, Kathleen Blondeau, Lieven Dupont and Daniel Sifrim

Centre for Gastroenterological Research KULeuven and Department of Pneumology, Gasthuisberg University Hospital, KULeuven, Belgium

Short title: Gastroesophageal reflux and chronic cough
All correspondence to:
Daniel Sifrim M.D., Ph.D
Faculty of Medicine K.U.Leuven
Lab G-I Physiopathology
O\&N Gasthuisberg, 7th floor
Herestraat 49, 3000, Leuven, Belgium.
Tel: +32.16 .345752$
Fax: +32.16 .345939$
e-mail:Daniel.Sifrim@med.kuleuven.ac.be 


\section{Abstract}

Gastroesophageal reflux (GER) is one of the three most common causes of chronic unexplained cough. Diagnosing GER related cough is challenging since many patients do not have esophagitis or an increased esophageal acid exposure during $24 \mathrm{~h}$ esophageal pH-metry. A significant time association between acid reflux and cough can be demonstrated in a subgroup of patients, even if the total esophageal acid exposure is normal. Establishing an exact time relationship between reflux and cough requires objective measurements of both cough and reflux episodes. A variety of techniques for cough assessment are available, including sound recordings and continuous measurement of gastroesophageal pressures. The Symptom Association Probability (SAP) has been suggested as the most reliable algorithm to establish the non-chance association between GER and cough. Although the relationship between acid reflux and cough is generally accepted, the response rate of patients with chronic unexplained cough to proton pump inhibitor treatment (PPI) is poorer compared to that in patients with typical GERD symptoms. Combined impedance-pH recordings, a new technique for the measurement of all types of reflux, have recently shown that not only acid but also weakly acidic GER may be associated with cough. Moreover, measurements in patients "on" PPI therapy demonstrated that weakly acidic reflux may persist during PPI treatment and may be associated with cough.

Aspiration of gastric contents into the lungs and a vagally mediated reflex arc, originating from the distal esophagus, have been proposed as pathophysiological mechanisms in GER-related cough. More recently, reflux induced bronchial hypersensitivity has been proposed as a third underlying mechanism.

Treatment of GER related cough remains challenging. So far, long term PPI treatments produce unsatisfactory results. In patients not responding to PPI, weakly acidic GER might still be the cause of cough. In these patients other therapeutic strategies i.e. abolishing all types of GER might need to be considered. Antireflux surgery has been performed successfully in a group of patients with GER related cough. However, controlled, prospective outcome studies are necessary to confirm the role of antireflux treatments in the management of GER related cough. 


\section{Introduction}

Gastroesophageal reflux (GER) can result into typical symptoms such as regurgitation and heartburn with or without esophagitis. [1] Gastroesophageal reflux disease (GERD) can also be associated with extraesophageal symptoms, such as chronic cough, asthma and laryngitis. [2]

Gastroenterologists often come across with patients having heartburn and/or regurgitation who also experience cough. On the other hand, pulmonologists are confronted with patients having chronic cough and heartburn. Increased GER is the third most common cause of chronic cough [3] and according to Jaspersen et al. cough is common either in erosive (30.5\%) and non-erosive (34.9\%) reflux disease. [4]

To better understand the relationship between reflux and cough and provide a rationale therapy, both gastroenterologists and pulmonologists should 1) optimize their selection of patients with suspicion of reflux-related cough, 2) use the most sensitive methods for reflux detection, 3) use an objective method of cough detection and 4) use a good statistical algorithm that excludes a chance association between reflux in cough in each individual patient.

\section{Patient selection}

Before considering increased GER as a cause of cough, gastroenterologists need to make sure that other causes of chronic cough like allergies, smoking, ACE inhibitors, cancer or asthma are thoroughly excluded. Likewise, pulmonologists should not consider or exclude the diagnosis of increased GER, in a patient with cough, only based on a symptom questionnaire. It is known that a high proportion of patients with GER-related chronic cough do not have heartburn or regurgitation. [5-8]

\section{Detection of gastroesophageal reflux}

Endoscopy will detect esophagitis in 30-50\% of patients with typical GER symptoms. [9] Patients with chronic cough without heartburn are unlikely to have esophagitis. [10] Twenty-four hour $\mathrm{pH}$ monitoring is considered the gold standard for diagnosis of GERD. Reflux episodes are defined as a $\mathrm{pH}$ drop below 4 for more than 10 seconds. Ph- 
monitoring is considered pathological if total esophageal acid exposure is higher than 4.5 $\%$ of the $24 \mathrm{~h}$ monitoring. Esophageal $\mathrm{pH}$ monitoring is limited to detection of acid reflux. More recently, a more sensitive ambulatory technique i.e. impedance-pH monitoring, has been introduced to measure both acid and non-acid reflux. [11] Our group first reported a possible involvement of non-acid reflux in the pathogenesis of chronic cough. $[12 ; 13]$

\section{Detection of cough}

To understand the association between cough and reflux, it is necessary to record cough episodes during reflux monitoring. Several methods are currently used. The most frequently used is a diary card where the patient writes the exact timing of significant cough bursts. The patient also can push an event marker in the reflux monitoring data logger. This is a simple method that identifies the daytime cough episodes that were significant for the patient. However, many cough events are not recorded, and also nocturnal cough is missed. Other methods have been developed for objective cough recording, including microphone based sound recording using computer algorithm for automatic cough recognition. So far this method has not been used during reflux monitoring. [14] Finally, a manometric technique has been suggested by Paterson et al. [15] This technique consists of adding to the reflux monitoring catheter, a second thin catheter containing pressure sensors located in the abdomen and thorax. Coughing provokes a typical pressure pattern artifact that is recognized in the simultaneous refluxpressure monitoring. In this way, cough episodes are identified objectively and the presence of reflux before the cough can easily be recognized during the preceding time window. (Figure 1) Using this technique, our group has analyzed the relationship between cough and reflux in 100 patients with unexplained chronic cough. [12;13]

\section{Statistical algorithm that excludes a chance association between reflux and cough}

During a $24 \mathrm{~h}$ ambulatory monitoring, many reflux and cough episodes may occur close together in time. Because of the large number of reflux and cough episodes, this might be due only by chance. If we want to address a possible causal association, we need first to identify cough episodes preceded by reflux. In order to exclude the chance association, 
between reflux and other symptoms like heartburn or chest pain, several mathematical algorithms were designed. [16]

The symptom index (SI) has been defined as the percentage of reflux associated symptom episodes and is considered positive if $\geq 50 \%$. The disadvantage of the SI is that it does not take into account the total number of reflux episodes that occur. This means that patients with a large number of reflux events and a small number of symptoms may have a positive SI by chance.

The symptom association probability (SAP) calculates the statistical relationship between symptoms and reflux episodes using the Fischer's exact test, taking into account the number of associated reflux-symptom episodes as well as the total number of reflux and symptom events. [17] For this the total twenty-four hour monitoring will be divided into frames of two minutes. A 2 minute period in which a reflux episode is detected, will be addressed as $\mathrm{R}+$. In the next step, we will determine for every symptom if it was preceded by reflux in a 2 minute frame $(\mathrm{R}+\mathrm{S}+)$. The Fisher's exact test will calculate the probability ( $p$ value) that the observed distribution could have occurred by chance. The SAP is calculated as (1-p)*100\% and is considered positive when higher than $95 \%$. [16]

It is important to acknowledge that a time window of 2 minutes was chosen as optimal to assess the association between heartburn/chest pain and GER. [18] The optimal time window to calculate the SAP between reflux and cough is still unknown. In recent studies we used impedance-pH monitoring for reflux detection and continuous manometry for objective cough detection in 100 patients with unexplained chronic cough. We calculated the SAP with a time window of 2 minutes and found that $36 \%$ of the patients had a non-chance time association between their reflux and cough.

\section{Pathophysiology of reflux-related cough}

Aspiration of gastric juices containing acid, pepsin, bile acids and duodenal pancreatic enzymes, is considered to be an important mechanism in the etiology of reflux-related cough. Pharyngeal $\mathrm{pH}$ recording that demonstrated micro-aspiration of gastric contents into the pharynx favor this hypothesis. [19]

In the past, detection of lipid-laden macrophages in bronchoalveolar lavage fluid (BALF) or sputum has been used as possible a marker for aspiration. Studies show that lipid-laden 
alveolar macrophages are present in $85 \%$ of children with chronic respiratory tract disorders and GER. [20;21] This method has low specificity and little is known on its prevalence in adult patients with chronic unexplained cough. [22;23]

BALF is tested on the presence of pepsin and/or bile acids to establish aspiration. Pepsin is found in BALF of almost all lung transplant patients and bile acids in half of the lung transplant patients. [24] It is not yet known which component of the refluxate is the most harmful to bronchial epithelial damage.

A vagal reflex arc originating from the distal esophagus after either exposure to acid or esophageal distention can cause cough. [25-27] Lidocaine, a topical anesthetic, blocks cough induction by distal esophageal acidification. [25] Furthermore, acidification of the esophagus can activate local axonal reflexes which can cause inflammation in the airway. A study of Patterson et al. showed that the presence of acid in the esophagus in asthma and chronic cough patients releases tachykinins such as substance $\mathrm{P}$ and neurokinin $\mathrm{A}$ into the lungs where they will cause bronchoconstriction and airway micro vascular leakage. [27]

Patients with GER and cough have higher cough sensitivity after perfusion of an acid solution into the distal esophagus compared to patients with GER without cough. [28]

If gastroesophageal reflux induces cough, why not all patients with increased GER have cough? Is there a specific difference in the refluxate or rather a hypersensitivity pattern in those patients with reflux-related cough?

We studied 100 patients with chronic unexplained cough. [13] A minority of these patients had an increased number of reflux episodes compared with asymptomatic controls. We studied in detail the characteristics of acid and weakly acidic reflux episodes temporally related to cough. A symptomatic reflux was defined as a reflux episode followed by cough in a two minute time window. Reflux episodes that occurred from 1 hour before to 1 hour after a symptomatic episode were considered as asymptomatic reflux controls. Symptomatic reflux episodes had a higher nadir $\mathrm{pH}$ (3.7) compared to asymptomatic reflux events (2.9). Furthermore, patients with a positive SAP between reflux and cough had more reflux episodes reaching the more proximal esophagus. [29] 
A positive SAP between reflux and cough was found in 36 of 100 patients (9 SAP+ for acid reflux, $23 \mathrm{SAP}+$ for weakly acidic reflux and $4 \mathrm{SAP}+$ for both acid and weakly acidic reflux). These results imply that in a number of patients weakly acidic reflux can be the potential mechanism for chronic cough. Because most of these patients did not have an elevated number of reflux events, we believe that hypersensitivity to one or more components (non acid) of the refluxate might play a role in the etiology of cough.

Previous studies revealed a higher prevalence of acid GER in patients with cystic fibrosis (CF). Moreover, CF patients with GER have a slightly poorer lung function than those without GER. [30]

As in patients with chronic cough, we performed combined $24 \mathrm{~h}$ impedance-pHmanometry studies in a group of $23 \mathrm{CF}$ adult patients. We found increased GER in a majority of the patients, mostly acid GER but with a subgroup having increased weakly acidic reflux. In these patients we found a significant correlation between esophageal acid exposure and the number of coughs $/ 24 \mathrm{~h}$. We also found that reflux is a primary event in $\mathrm{CF}$, and not a consequence of coughing. Only a small portion of the esophageal acid exposure and volume exposure was caused by cough. [31]

\section{Treatment of reflux related cough}

If increased GER can provoke chronic cough, treatment of GER should reduce cough. However, results of antireflux therapy in patients with cough are somehow disappointing. Kiljander et al. showed improvement of cough in $72 \%$ of the patients in a placebo controlled study with PPI's. [32] On the contrary, other studies have shown a less good response rate. [33;34] In many of these studies, patients were asked to fill in a questionnaire about their symptoms, without using objective measurement for cough.

Since it has been established that weakly acidic reflux could be a possible cause of chronic cough, treatment of cough-related weakly acidic reflux should be considered. The main mechanism for weakly acidic reflux are transient lower esophageal sphincter (LES) relaxations. Baclofen is a $\gamma$-aminobutyric acid agonist ( $\mathrm{GABA}_{\mathrm{B}}$-agonist) that reduces the number of reflux episodes by reducing the number of transient LES relaxations. Baclofen reduces weakly acidic reflux [35] and has also an antitussive effect. However, baclofen 
has side effects like nausea and sedation and it is not well tolerated by several patients. New GABA $_{B}$-agonists with less neurological side effects are under development.

Azithromycin (AZI) belongs to the group of macrolide antibiotics, which are known to have prokinetic effects, and is often used in lung transplant patients (LTx). Lung transplantation has become an effective therapeutic option for end-stage pulmonary diseases, improving quality of life and prolongating survival. [36] An important factor in the long term outcome of these patients is the development of chronic allograft rejection (bronchiolitis obliterans syndrome, BOS), which is identified as a persistent drop in $\mathrm{FEV}_{1}$ after transplantation. [36] Since GER has been implicated as a potential factor in the etiology of BOS, many studies have been done trying to clarify their relationship. In LTx, standard esophageal $\mathrm{pH}$-monitoring revealed an increased acid exposure in $70 \%$ of the patients. [37;38]

We studied the effect of AZI on gastroesophageal reflux in LTx and found that AZI reduced esophageal acid and volume exposure as well as the number of proximal reflux events. [39] Furthermore, AZI reduced the concentration of bile acids found in BALF in these patients suggesting that GER and the risk of aspiration decreases on AZI. [40] In patients with clearly demonstrated association between reflux and cough but no response to full treatment with PPI's, antireflux surgery has been proposed. The rationale, being the persistence of non-acid reflux in spite of PPI's. So far, uncontrolled studies are encouraging [41-43], and there is a need for new outcome controlled studies with objective cough measurements before and after surgery to consolidate the recommendation for antireflux surgery in patients with chronic cough not responding to PPI's. 
Figure Legend:

Figure 1: Tracing of esophageal impedance-pH combined with manometry: example of a weakly acidic reflux followed by a cough burst. Impedance tracing shows a retrograde movement of a liquid bolus, with a drop in esophageal $\mathrm{pH}$ of more than $1 \mathrm{pH}$ unit but remaining above 4 (weakly acidic reflux). A cough burst is shown manometrically as phasic, short duration, rapid pressure rises occurring simultaneously and with the same pressure configuration at all manometric recording sites. Cough occurred 25.4 seconds after the onset of a weakly acidic reflux event. 


\section{Reference List}

[1] Vakil N, Van Zanten SV, Kahrilas P et al. [The Montreal definition and classification of gastroesophageal reflux disease: a global, evidence-based consensus paper]. Z Gastroenterol 2007;45(11):1125-40.

[2] Richter JE. Review article: extraoesophageal manifestations of gastrooesophageal reflux disease. Aliment Pharmacol Ther 2005;22 Suppl 1:70-80.

[3] Irwin RS, Corrao WM, Pratter MR. Chronic persistent cough in the adult: the spectrum and frequency of causes and successful outcome of specific therapy. Am Rev Respir Dis 1981;123(4 Pt 1):413-7.

[4] Jaspersen D, Kulig M, Labenz J et al. Prevalence of extra-oesophageal manifestations in gastro-oesophageal reflux disease: an analysis based on the ProGERD Study. Aliment Pharmacol Ther 2003;17(12):1515-20.

[5] Irwin RS, Curley FJ. Is the anatomic, diagnostic work-up of chronic cough not all that it is hacked up to be? Chest 1989;95(4):711-3.

[6] Irwin RS, Curley FJ, French CL. Chronic cough. The spectrum and frequency of causes, key components of the diagnostic evaluation, and outcome of specific therapy. Am Rev Respir Dis 1990;141(3):640-7.

[7] Irwin RS. Chronic cough due to gastroesophageal reflux disease: ACCP evidencebased clinical practice guidelines. Chest 2006;129(1): 80S-94S

[8] Waring JP, Lacayo L, Hunter J et al. Chronic cough and hoarseness in patients with severe gastroesophageal reflux disease. Diagnosis and response to therapy. Dig Dis Sci 1995;40(5):1093-7.

[9] Fass R. Erosive esophagitis and nonerosive reflux disease (NERD): comparison of epidemiologic, physiologic, and therapeutic characteristics. J Clin Gastroenterol 2007;41(2):131-7. 
[10] Jaspersen D. Extra-esophageal disorders in gastroesophageal reflux disease. Dig Dis 2004;22(2):115-9.

[11] Silny, J. Intraluminal multiple electric impedance procedure for meaurement of gastrointestinal motility. 3, 151-62. 1991.

Ref Type: Generic

[12] Sifrim D, Dupont L, Blondeau K et al. Weakly acidic reflux in patients with chronic unexplained cough during 24 hour pressure, $\mathrm{pH}$, and impedance monitoring. Gut 2005;54(4):449-54.

[13] Blondeau K, Dupont LJ, Mertens V et al. Improved diagnosis of gastrooesophageal reflux in patients with unexplained chronic cough. Aliment Pharmacol Ther 2007;25(6):723-32.

[14] Coyle MA, Keenan DB, Henderson LS et al. Evaluation of an ambulatory system for the quantification of cough frequency in patients with chronic obstructive pulmonary disease. Cough 2005;1:3.

[15] Paterson WG, Murat BW. Combined ambulatory esophageal manometry and dual-probe $\mathrm{pH}$-metry in evaluation of patients with chronic unexplained cough. Dig Dis Sci 1994;39(5):1117-25.

[16] Bredenoord AJ, Weusten BL, Smout AJ. Symptom association analysis in ambulatory gastro-oesophageal reflux monitoring. Gut 2005;54(12):1810-7.

[17] Weusten BL, Roelofs JM, Akkermans LM et al. The symptom-association probability: an improved method for symptom analysis of 24-hour esophageal $\mathrm{pH}$ data. Gastroenterology 1994;107(6):1741-5.

[18] Lam HG, Breumelhof R, Roelofs JM et al. What is the optimal time window in symptom analysis of 24-hour esophageal pressure and $\mathrm{pH}$ data? Dig Dis Sci 1994;39(2):402-9. 
[19] Oelschlager BK, Quiroga E, Isch JA et al. Gastroesophageal and pharyngeal reflux detection using impedance and 24-hour $\mathrm{pH}$ monitoring in asymptomatic subjects: defining the normal environment. J Gastrointest Surg 2006;10(1):54-62.

[20] Ahrens P, Noll C, Kitz R et al. Lipid-laden alveolar macrophages (LLAM): a useful marker of silent aspiration in children. Pediatr Pulmonol 1999;28(2):83-8.

[21] Parameswaran K, Anvari M, Efthimiadis A et al. Lipid-laden macrophages in induced sputum are a marker of oropharyngeal reflux and possible gastric aspiration. Eur Respir J 2000;16(6):1119-22.

[22] Koksal D, Ozkan B, Simsek C et al. Lipid-laden alveolar macrophage index in sputum is not useful in the differential diagnosis of pulmonary symptoms secondary to gastroesophageal reflux. Arch Med Res 2005;36(5):485-9.

[23] Krishnan U, Mitchell JD, Tobias V et al. Fat laden macrophages in tracheal aspirates as a marker of reflux aspiration: a negative report. J Pediatr Gastroenterol Nutr 2002;35(3):309-13.

[24] Blondeau K, Mertens V, Vanaudenaerde BA et al. Acid, non-acid GER and gastric aspiration in lung transplant patients with or without chronic rejection. Eur Respir J 2007.

[25] Ing AJ, Ngu MC, Breslin AB. Pathogenesis of chronic persistent cough associated with gastroesophageal reflux. Am J Respir Crit Care Med 1994;149(1):160-7.

[26] Irwin RS, Zawacki JK, Curley FJ et al. Chronic cough as the sole presenting manifestation of gastroesophageal reflux. Am Rev Respir Dis 1989;140(5):1294300.

[27] Patterson RN, Johnston BT, Ardill JE et al. Increased tachykinin levels in induced sputum from asthmatic and cough patients with acid reflux. Thorax 2007;62(6):491-5. 
[28] Javorkova N, Varechova S, Pecova R et al. Acidification of the oesophagus acutely increases the cough sensitivity in patients with gastro-oesophageal reflux and chronic cough. Neurogastroenterol Motil 2008;20(2):119-24.

[29] Blondeau K, Mertens V, Dupont L et al. Characteristics of acid and weakly acidic reflux temporally related to cough. Gastroenterology 2006;130(4):A634.

[30] Stringer DA, Sprigg A, Juodis E et al. The association of cystic fibrosis, gastroesophageal reflux, and reduced pulmonary function. Can Assoc Radiol J 1988;39(2):100-2.

[31] Blondeau K, Dupont L, Mertens V et al. Gastroesophageal reflux and aspiration of gastric contents in adult patients with cystic fibrosis. Gut 2008.

[32] Kiljander TO, Salomaa ER, Hietanen EK et al. Chronic cough and gastrooesophageal reflux: a double-blind placebo-controlled study with omeprazole. Eur Respir J 2000;16(4):633-8.

[33] Ours TM, Kavuru MS, Schilz RJ et al. A prospective evaluation of esophageal testing and a double-blind, randomized study of omeprazole in a diagnostic and therapeutic algorithm for chronic cough. Am J Gastroenterol 1999;94(11):3131-8.

[34] Poe RH, Harder RV, Israel RH et al. Chronic persistent cough. Experience in diagnosis and outcome using an anatomic diagnostic protocol. Chest 1989;95(4):723-8.

[35] Vela MF, Tutuian R, Katz PO et al. Baclofen decreases acid and non-acid postprandial gastro-oesophageal reflux measured by combined multichannel intraluminal impedance and pH. Aliment Pharmacol Ther 2003;17(2):243-51.

[36] Trulock EP, Edwards LB, Taylor DO et al. Registry of the International Society for Heart and Lung Transplantation: twenty-third official adult lung and heartlung transplantation report--2006. J Heart Lung Transplant 2006;25(8):880-92. 
[37] Benden C, Aurora P, Curry J et al. High prevalence of gastroesophageal reflux in children after lung transplantation. Pediatr Pulmonol 2005;40(1):68-71.

[38] D'Ovidio F, Mura M, Ridsdale R et al. The effect of reflux and bile acid aspiration on the lung allograft and its surfactant and innate immunity molecules SP-A and SP-D. Am J Transplant 2006;6(8):1930-8.

[39] Blondeau K, Mertens V, Vanaudenaerde B et al. The macrolide antibiotic azithromycin reduces gastroesophageal reflux in lung transplant patients. Gastroenterology 2007;132(4):A594.

[40] Mertens V, Blondeau K, Vanaudenaerde BM et al. Azithromycin red uces bile acid aspiration in lung transplant recipients. Journal of Heart and Lung Transplantation 2008;27(2):S124.

[41] Mainie I, Tutuian R, Agrawal A et al. Fundoplication eliminates chronic cough due to non-acid reflux identified by impedance $\mathrm{pH}$ monitoring. Thorax 2005;60(6):521-3.

[42] Mainie I, Tutuian R, Agrawal A et al. Combined multichannel intraluminal impedance-pH monitoring to select patients with persistent gastro-oesophageal reflux for laparoscopic Nissen fundoplication. Br J Surg 2006;93(12):1483-7.

[43] Tutuian R, Mainie I, Agrawal A et al. Nonacid reflux in patients with chronic cough on acid-suppressive therapy. Chest 2006;130(2):386-91. 


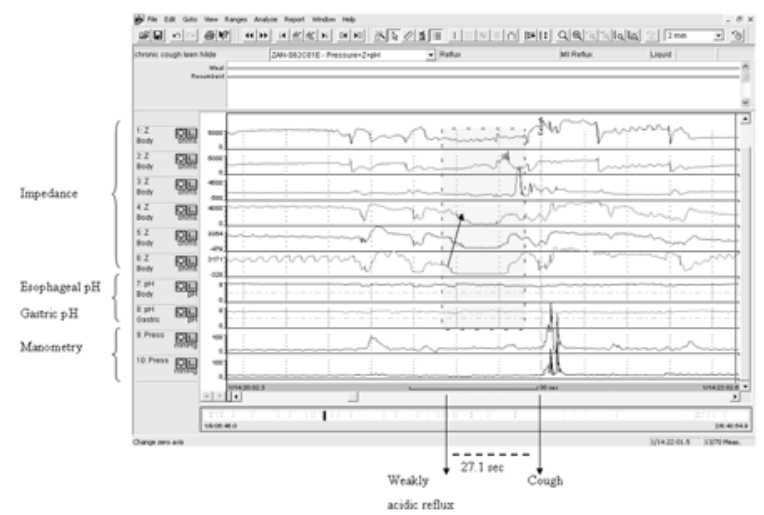

